\title{
Hierarchical scaling of marketing decision support systems
}

\author{
Berend Wierenga ${ }^{\text {a,* }}$, Peter A.M. \\ Oude Ophuis ${ }^{b}$, Eelko K.R. Huizingh ${ }^{c}$, \\ Peter A.F.M. van Campen ${ }^{\mathrm{d}, 1}$ \\ ${ }^{a}$ Erasmus University Rotterdam, Rotterdam School of Manage- \\ ment, P.O. Box 1738, 3000 DR Rotterdam, The Netherlands \\ ${ }^{b}$ Agricultural University Wageningen, P.O. Box 9101 Wagenin- \\ gen, The Netherlands \\ ${ }^{c}$ University of Groningen, P.O. Box 72, 9700 AB Groningen, \\ The Netherlands \\ ${ }^{d}$ Erasmus University Rotterdam, P.O. Box 1738, 3000 DR \\ Rotterdam, The Netherlands
}

Marketing Decision Support Systems (MDSS) show a large variety in functionality and form. In this paper a scale is developed that measures the sophistication of a Marketing Decision Support System. This scale, based on Guttman's Scalogram Analysis, is hierarchical in nature: more sophisticated MDSS have (also) the capabilities of less sophisticated systems but not the other way around. Items, used to construct the scale, are the presence or absence of specific functional features in a particular MDSS. The scale was applied to the marketing decision support systems of 194 Dutch companies and passed the consistency tests for a Guttman scale. Also the scale values appeared to correlate with specific company variables (size, industry, number of data sources etc.) in an interpretable way. Although this one-dimensional sophistication scale was specifically developed for Marketing Decision Support Systems, the concept is very well applicable to Decision Support Systems in general. Such a scale can contribute to a more systematic approach in the empirical study of Decision Support Systems.

Keywords: Marketing decision support systems; Decision support systems; Hierarchical scaling; Guttman scalogram analysis; Sophistication of a marketing decision support system; Functionality

\footnotetext{
* Corresponding author.

1 Now with Heineken Nederland.
}

\section{Introduction}

Decision Support Systems (DSS) in companies and other organisations show a large variety in levels of sophistication and differences in depth and breath of application. The actual form of DSS $^{2}$ also shows a broad spectrum: database management systems, spreadsheets, statistical

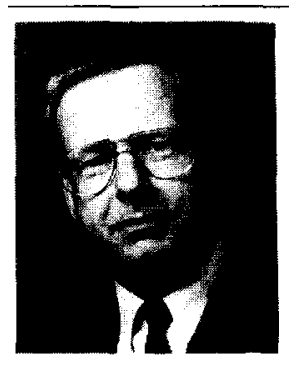

Berend Wierenga is Professor of Marketing at the Rotterdam School of Management of the Erasmus University of Rotterdam. He received a Ph.D. in Marketing from the Wageningen Agricultural University and is Professor of Marketing at the Erasmus University since 1983. His major research interests are in Marketing Decision Support Systems and Marketing Knowledge Based Systems. He has published widely in Dutch and International Journals such as International Journal of Research in Marketing, European Journal of Operational Research, Journal of Marketing Research and Journal of Marketing.

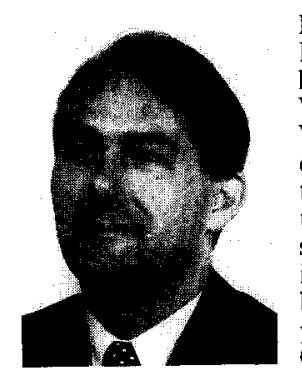

Peter A.M. Oude Ophuis is Assistant Professor at the Department of Marketing and Marketing Research of Wageningen Agricultural University, Wageningen, The Netherlands. The edge between marketing and information technology has been an important inspiration for some of his re search activities. His other research interests are in the field of consumer behavior and marketing strategy, with particular emphasis on the domain of (fresh) foods.

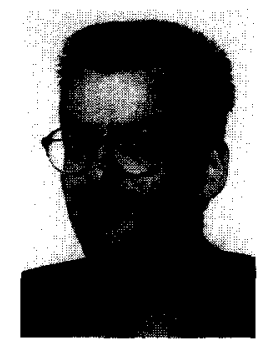

Eelko K.R.E. Huizingh is assistant professor of Information Systems at the Department of Business Administration and Management Sciences of the University of Groningen. He received his Ph.D. for a dissertation on Marketing Information Systems. His major research interests are in the application of information technology to improve the marketing management process, e.g. marketing information systems, marketing decision support systems, and marketing expert systems, performance measures for decision support systems, and end-user computing. He has published papers in many journals in the Netherlands and in the Proceedings of several International Conferences. 
packages, simulation software etc. In order to study DSS as can be observed in practice, a system is needed that is able to classify DSS into relevant categories. The concept of DSS as such is too broad for analytical purposes.

Since the days of Linnaeus it is known that empirical research always starts with a classification system for the phenomena observed. This paper deals with the development of such a classification system for Decision Support Systems in the area of marketing. It is surprising how little work seems to have been done on the topic of classification of Decision Support Systems. The most important contribution in this area was made by Alter [1], [2] and [3]. He distinguishes seven different classes of DSS, ranging from "file drawer systems" to "optimalization" and "suggestion models". The more recent DSS literature e.g. [28] seems to focus on the distinction between DSS with an emphasis on data management versus DSS with an emphasis on model management. Examples of papers that emphasize data management are: [7], [24] and [27]. Others, e.g. [4], [10], [20], [25] and [31] focus on the model management aspect of DSS.

However, a dichotomy: data management versus model management seems too simple as a classification system for the rich empirical reality of DSS in companies and other organisations. Many systems have features of both. A more detailed classification system for DSS is desirable.

In this paper a classification system will be developed for Decision Support Systems based on the sophistication of the system, i.e. what types of questions the system can answer. Al-

${ }^{2}$ In this paper the abbrevation DSS can stand for the plural Decision Support Systems, as well as for the singular Decision Support System. The same applies to the term MDSS (Marketing Decision Support Systems), to be introduced later.

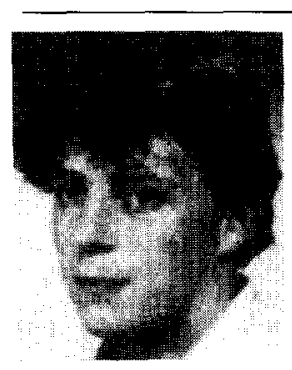

Peter A.F.M. van Campen is currently working at the marketing department of Heineken Netherlands, responsible for the consumer marketing of the Heineken brand. Peter received his M.Sc. degree in business administration at the Erasmus University Rotterdam, The Netherlands and a postgraduate diplome from The London School of Economics, United Kingdom. His interests include the use of information technology in the marketing decision making process. though this paper is restricted to DSS in a specific area i.e. marketing, this approach seems to be applicable to DSS in general.

The classification system introduced here

i. focusses on the functionality of a system and not on the actual form in which the DSS appears (spreadsheets, statistical packages etc.);

ii. is hierarchical: on the basis of theoretical considerations it can be hypothesized that there is a hierarchical ordering of functional capabilities of DSS: systems with a specific functional capability A will also have - the less sophisticated - functional capability B, but not necessarily the other way around;

iii. has five different levels, which can be interpreted as (increasing) levels of sophistication of the DSS.

The remainder of this paper will first discuss the theoretical/conceptual notions that form the basis for the classification system for Marketing Decision Support Systems (MDSS). It appears that Guttman's scalogram analysis (actually an extension thereof) is a suitable tool to develop and test a scale for this classification system. Therefore, the subsequent paragraph will deal with Guttman's scalogram analysis and the items and measurements used in the context of MDSS. Then the actual operationalisation is dealt with which turned out to give satisfactory results for the scale in terms of internal consistency and monotonicity in a sample of 194 companies.

Finally, the scores on the scale are correlated with such company characteristics as total revenue, number of employees, size of marketing department and many other variables. This gives an impression of the face validity of the scale.

\section{Theoretical basis of a hierarchical scale for marketing decision support systems}

The research project was started with a review of the marketing and decision support system literature. The initial goal of this review was to find characteristics with which MDSS could be distinguished from other kinds of marketing information systems.

Marketing has a long tradition in the area of information/modeling systems.

As early as 1969 Montgomery and Urban de- 
signed what they called an "Information System" to support managerial decision making in marketing [22]. Later on this "Information System" has been renamed by Little [15] as a "Marketing Decision Support System". The original Montgomery and Urban system contained four basic components which have become classic since then: the Data Bank, the Statistical Bank, the Model Bank and the User Interface.

Little (1979) gives the following definition of a Marketing Decision Support System (MDSS):

"A marketing decision support system is a coordinated collection of data, systems, tools and techniques with supporting software and hardware by which an organisation gathers and interprets relevant information from business and environment and turns it into a basis for marketing action."

Using the terminology of the DSS-literature [29], [30], Marketing Decision Support Systems can be defined as:

"Interactive computer systems that support marketing decision makers to use data and models to solve unstructured problems."

Would it be possible to use the components mentioned in these definitions to decide whether or not a particular system qualifies as a (Marketing) DSS?

First, the question is which component(s) should be used as criteria. One possibility is to choose a minimum approach and to conclude that a company has a MDSS if any component mentioned in the definition of a MDSS is present. The first definition, given above, explicity mentions data and models as components of a MDSS. Little's definition stipulates: data, systems, tools, techniques, software and hardware. Montgomery and Urban refer to data, statistics and models. Data appears as a term in all three descriptions. Since most companies use at least some data to base marketing decisions on, a minimum definition would not be very discriminating: practically every information system would be a MDSS.

The other possibility is to use a "conjunctive" definition, implying that a company's system would only qualify as a MDSS if the system meets all of a number of explicit criteria. This would lead to different classifications dependent on which criteria are included. If the maximum list of criteria is applied one would end up with few real MDSS.
So is it useful at all to define a (M)DSS as a zero-one variable so that a company either has or does not have a MDSS? In our opinion it is much more meaningful to have a scale with several levels expressing something about the "quality" or "advancedness" of a MDSS.

Our basic idea that is marketing decision support systems can be ordered according to a onedimensional concept which we call "sophistication". Sophistication refers to degree of difficulty of the questions an MDSS is able to answer. Sophistication is a "latent construct". The actual level of sophistication is to be derived from the specific characteristics of the MDSS. The scale that is developed in this paper enables the user to determine the position of a company's MDSS on this sophistication scale on the basis of a number of observable features of the particular MDSS.

Before we turn to the actual measurement issue, first we have to determine the content of this sophistication scale: what do we want to measure with it?

Conceptually a scale for a Marketing Decision Support System could have the following levels. The lowest point (zero level) of the scale would refer to the situation when no analytic tool whatsoever is used to support marketing decisions.

The next position of the scale would be a system for "status reporting": to answer the question: "what happened". Probably many systems that are currently used do not go beyond this point of reporting the status of sales, market share, price, advertising efforts, competitive marketing actions etc. Increasingly, though, this type of information is given not only at the market level, but also at the level of submarkets: per region, per segment, per variety type etc.

One step further would be to ask for the causes of the observed events: "why did it happen?" Little [15] called this "response reporting": how do sales react to changes in advertising efforts, price changes, etc. He predicted a shift from status reporting to market response reporting. In terms of Montgomery and Urban's components, elements of the Statistics Bank are needed to analyze the events in the market. Techniques such as analysis of variance, regression and discriminant analysis can be used to study the relationship between sales and its influencing factors such as personal selling effort, advertising, sales promotion and actions performed by competitors. 
When insights have been obtained into the causes of events in the market, the next question can be asked: "what happens if?" Here, the interest is in predicting the effects of specific marketing actions which are being considered. One might also be interested in getting estimates of the impact of specific likely actions of competitors. To be able to predict the effects of specific changes in the market on variables such as sales, market shares, profits, etc. one needs to have models (from Montgomery and Urban's "Model Bank") that specify the relationship between the variables in a market. These models can then be used to simulate the effects of specific events.

Finally, the question arises of the best action or strategy in a specific situation: "what should happen?" Since the purpose of the system is to help a marketing manager to decide which actions to take to make specific things to happen we might also phrase this as: "what should be done?" To answer this question a company has to specify its objective(s) and, then - using the model describing the mechanism in the market - attempt to find the policy or strategy which will maximize the objective (e.g. market share, profit). To find the best option some optimization method is required.

These four questions: What, why, what if and what should constitute a hierarchy for the functionality of a MDSS. A system has a functionality

Table 1

A hierarchy of marketing questions and the corresponding functionality of a MDSS

\begin{tabular}{lll}
\hline $\begin{array}{l}\text { Level } \\
\text { qupe of marketing }\end{array}$ & Functionality of the system \\
\hline $1 \quad$ What happened & $\begin{array}{l}\text { Can provide information about } \\
\text { customers, sales, competitors, } \\
\text { advertising, sales promotion } \\
\text { etc. } \\
\text { Can analyze the effects of own } \\
\text { and competitors' marketing } \\
\text { actions; analyzes } \\
\text { causes of changes in the market } \\
\text { Can predict the effect of } \\
\text { marketing instruments; uses } \\
\text { mathematical models } \\
\text { to compute the outcome of } \\
\text { actions }\end{array}$ \\
& What will happen if? & $\begin{array}{l}\text { Can find the best marketing } \\
\text { strategy in a given situation: } \\
\text { performs optimization }\end{array}$ \\
& What should happen
\end{tabular}

level 1 when it can only answer "what-questions". A system has functionality level 2 if it can answer "why questions" etc. Table 1 gives the functionality of a MDSS that is required for each of the four questions.

Up to now this hierarchy is only a hypothesis. Whether or not the actual MDSS that can be observed in companies can be indeed ordered according to such a one-dimensional hierarchical scale is an empirical question. If the hierarchy really exists, this would imply that e.g. a system that can answer the "what should-question" is also able to answer the "what-if-question". Furthermore, a system that can do analysis (i.e. answer the "why question") should also be able to provide status information (answer the "whatquestion"). These statements however, cannot be reversed: a system capable to do what-if analysis does not necessarily also offer what-should analyses.

Guttman's scalogram analysis offers a framework to develop and empirically test this Hierarchical MDSS Sophistication (HMS) scale. This will be elaborated in the next paragraph.

There is some similarity between the classification system proposed here and the one developed by Alter (Ibid). After having studied 56 DSS Alter classified them into seven categories: file drawer systems, data analysis systems, analysis information, accounting models, representational models, optimizational models, and suggestion models. The main distinction is made between data oriented DSS (the first three categories) and model oriented DSS (the latter four categories). Alter's conclusion that information systems tend to support data management first and then model management, is supported by others [27], [12].

Alter orders decision support systems according to what he calls "degree of action implication of system outputs, i.e. the degree to which the system's outputs can directly determine the decision" [2]. In Alter's classification system a hierarchy similar to the above mentioned four questions (what, why, what if, and what should) can be found: data retrieval, data analysis, simulation and suggestion. A comparable classification can also be found in [23], although the categorization there is limited to only the first three questions.

However, Alter's term "degree of action implication of system outputs" would not apply to the different levels of the classification system dis- 
cussed here. Systems as low as level 1, which only contain data about markets (e.g. the system may show a loss in marker share) can have important action implications. The different levels in the proposed system stand for the level of sophistication of the analysis underlying a particular action.

A second important difference with Alter's system is the explicit hierarchy of the proposed scale. Alter's system can be seen as only preluding to such a hierarchy already in that the first two categories refer to data oriented DSS and the last three to model oriented DSS.

Thirdly, Alter did not analyze the correlation of his scale with company characteristics.

The scale proposed here can also be related to the well-known components of a MDSS, as described by Little [15]: Data (What), Statistics (Why), Models (What if) and Optimization (What should). Little did not put these components in an explicit hierarchical order however. The distinction between the "Why" and "What-if" question as we use in our scale was also made by Little. The Why-question specifically refers to statistical analysis: e.g. the computation of correlation coefficients between advertising expenditures and sales. What-if models deal with the expected effects of marketing actions on quantities such as sales, market share etc. These expected effects can be based on statistical analysis of (historical) data, but a what-if model can also be based on other knowledge, for example the judgment of experienced marketers. An example of the latter type of what-if model is Little's Decision Calculus approach [14].

\section{Guttman's scalogram analysis and extensions}

As mentioned before, the concept of "sophistication of a MDSS" can be considered as a latent variable that is not directly observable. However features of the MDSS that can be observed, e.g. the data types it contains, the purposes it can be used for, are assumed to be related to this underlying (or latent) dimension. What we want to do is "to construct a typology from a combination of values of several consistent variables", McCutcheon [18, p. 6]. These consistent variables are pre-dominantly of a categorical nature. In such an approach called "latent class analysis", the result is an ordinal scale for the latent variable.
Table 2

Question in the survey which relate to the 4 items: what, why, what-if and what should

\begin{tabular}{|c|c|c|}
\hline & & Use of MDSS for \\
\hline \multirow[t]{7}{*}{ 'What' items } & 1 & Retrieval of data about customers \\
\hline & 2 & Retrieval of data about products \\
\hline & 3 & $\begin{array}{l}\text { Retrieval of data about } \\
\text { competitors }\end{array}$ \\
\hline & 4 & Retrieval of data about sales areas \\
\hline & 5 & $\begin{array}{l}\text { Tracking of developments of sales } \\
\text { in the market }\end{array}$ \\
\hline & 6 & $\begin{array}{l}\text { Tracking of developments of } \\
\text { advertising and promotion in the } \\
\text { market }\end{array}$ \\
\hline & 7 & $\begin{array}{l}\text { Tracking major changes in the } \\
\text { market }\end{array}$ \\
\hline \multirow[t]{2}{*}{ 'Why' items } & 1 & Analyzing own marketing actions \\
\hline & 2 & Analyzing market changes \\
\hline \multirow[t]{3}{*}{ 'What-if' items } & 1 & $\begin{array}{l}\text { Forecasting the effects of different } \\
\text { marketing strategies }\end{array}$ \\
\hline & 2 & $\begin{array}{l}\text { Performing calculations using } \\
\text { mathematical models }\end{array}$ \\
\hline & 3 & $\begin{array}{l}\text { Predicting the effects of marketing } \\
\text { actions }\end{array}$ \\
\hline 'What-should' items & 1 & $\begin{array}{l}\text { Finding the optimal marketing } \\
\text { strategy }\end{array}$ \\
\hline
\end{tabular}

It should be emphasized that the four questions of Table 2 form a positive (hierarchical) scale and not a normative scale in the sense that a company ought to be at the highest level of the MDSS scale possible.

The scaling model that was originally developed by Louis Guttman [9] and is known as Scalogram Analysis is a suitable tool to test the existence of a one-dimensional hierarchy and to actually develop the scale. In the field of marketing Guttman's scalogram analysis was used earlier for the analysis of the order in which consumers purchase consumer durables [5], [19] and in a study of media exposure [13]. It is suspected that Guttman's scalogram analysis has not been used before in the field of information systems.

The (underlying) latent variable in Guttman scaling is of an ordinal level, whereas the inputs are categorical: whether or not the system has a specific functionality.

Because of the categorical nature of the variables we cannot use scales such as the Likert scale here.

Scalogram analysis is based on an analysis of the response patterns of subjects to a set of items, where a response pattern denotes the set of re- 
sponses to dichotomous items given by a subject. With $n$ dichotomous items, $2^{\mathrm{n}}$ response patterns are possible. If the items form a hierarchical scale, only $n+1$ of these patterns will occur (see the following example). The nonoccurrence (or relative nonoccurrence) of the deviant patterns enables the scalogram procedure to recover the order of the individuals and/or category boundaries on the underlying continuum from the observed data [32].

With respect to the choice of the Guttman scale it should be noted that in this study we determine the level of sophistication of a Marketing Decision Support System on the basis of objective (yes-no) features of the system. An interesting question would be how this "objective" level of sophistication corresponds to the subjective perceptions the users have of the system. For that purpose Likert-type scales could be developed to measure, for example, how "actionable" (i.e. to what extent the system outcomes can be translated in marketing actions), reliable, precise etc. the system is. A set of such scales together would produce a "perceived" level of sophistication. Since such perceptual data were not collected in the present study, this is left to future research.

The basic principle of scalogram analysis will be explicated with an example, which was adapted from Guttman's original article [9]. Suppose, a set of items is available that can be used to assess asserted individual calculus problem solving capability. Respondents will be asked to indicate if they are capable to solve the following problems:

(a) What is the sum of $2+2$ ?

(b) What is the result of multiplying 24 by 48 and dividing this product by 288 ?

(c) What is the natural logarithm of $\mathrm{e}^{2 \mathrm{x}}$ ?

For each item the answer is yes (Y) when one indicates being capable to solve the question and no $(\mathrm{N})$ when one is not capable of solving it ${ }^{3}$. On the basis of responses to these three dichotomized items there are $2 \times 2 \times 2=8$ possible types of response patterns. However, if these items were given to high school students probably only four patterns would occur. There would be

\footnotetext{
${ }^{3}$ In this example respondents are asked to indicate their capability. We could also have asked respondents to produce a solution, which can be compared with the correct answer and rated as correct or false.
}

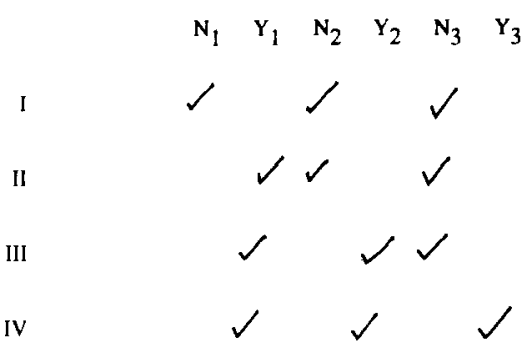

Fig. 1. Scalogram of 3 dichotomous items.

respondents who indicated being capable of solving all three problems (YYY), respondents who could only solve the first two items (YYN), respondents who could solve the first item only (YNN) and respondents who could solve none of the problems (NNN). The reason for nonoccurrence of other types of response patterns lies in the fact that these three items represent different levels in the assumed continuum of calculus problem solving capability. It is unlikely, for example, that a respondent would know the answer for question (c) and not for (a) and (b), which would correspond to response pattern: NNY.

Scalogram analysis is a procedure to investigate if items form a scale or, more specifically, if only the expected response patterns are present. For the four types of respondents, the results are shown in the chart in Figure 1, where the rows represent the four response patterns and the columns represent the yes / no categories for each item. This chart is called a scalogram.

As presented in Figure 1 the scalogram does not provide easy insight into the scalability of the items, but when the columns are rearranged as in Figure 2 it is clear that the items form a scale.

The "parallelogram" pattern (hence the name the scalogram) is a necessary and sufficient condition to consider the dichotomous items as representing a scale of an underlying continuum.

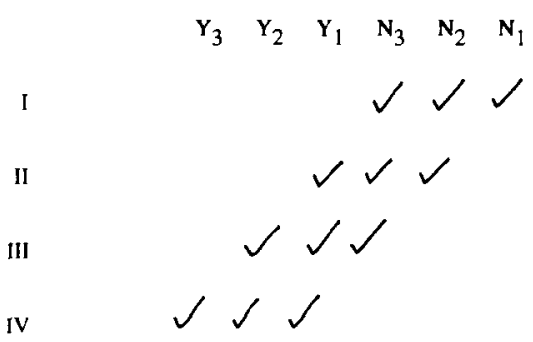

Fig. 2. Scalogram of 3 dichotomous items after re-arrangement. 
This scaling model, originally developed by Guttman, places strong restrictions on the available data. When the model is valid, respondents that satisfy the more difficult item have to satisfy the less difficult items. This implies that for each pair of items a cross-tabulation can be made that has at least one empty cell, as is shown in Figure 3.

If item $i$ is more difficult than item $j$ the $i(+) j(-)$ cell should be empty. Such an assumption rarely holds for actual data. This means that the conditions for a truly deterministic Guttmanmodel seldom hold. The limitations of the deterministic nature of the Guttman scaling model were overcome by Mokken who developed a probabilistic version of the Guttman approach for dichotomous items that has become known as the Mokken scale analysis [21]. Mokken extended a criterion of scalability of items, which was originally developed by Loevinger as a measure for the homogeneity of two items of a homogeneous test [16], [17].

The scalability of two items $(i$ and $j$ ) can be estimated or tested by means of the scalability coefficient $H_{i j}$, which is defined as

$H_{i j}=1-\frac{F_{i j}}{E_{i j}}$

where $F_{i j}$ : is the observed number of errors according to the Guttman scale model (i.e. in the dichotomous case the observed number of respondents that give a negative response to the easier and a positive response to the more difficult item);

and $E_{i j}:$ is the expected number of errors, as suming that the responses to the items are independent across persons and the marginals are fixed.

With the following example in Figure 4 the computation of $H_{i j}$ can be illustrated.

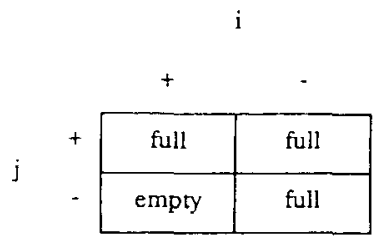

Fig. 3. Cross-tabulation of frequencies of categories of two dichomous items ( $i$ more difficult than $j$ ).

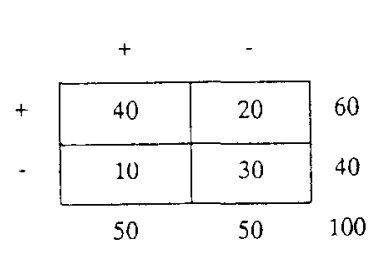

Fig. 4. Example of a cross-tabulation of frequencies for an item pair ( $i$ is more difficult than $j$ ).

In Figure 4, results of responses to two items $i$ and $j$ are summarized for a fictive sample of 100 respondents. Forty respondents who scored positively to item $j$ scored also positively to item $i$, which is supposed to be the more difficult item and therefore to be higher in the hierarchy than item $j$. Thirty respondents had negative scores for both items and twenty respondents had a positive score for $j$, but a negative score for $i$, while the reverse occurred for 10 respondents. It is exactly this last group that does not score in correspondence with the Guttman model. How serious this deviation is can be assessed by calculating the scalability coefficient $H_{i j}$, that can easily be calculated from this two by two table:

$F_{i j}=10$ and $E_{i j}=(50 \times 40) / 100=20$,

so $H_{i j}=1-10 / 20=0.50$.

Note that the reverse $H_{i j}$ would be much less $(0.33)$ !

The closer $H_{i j}$ is to its maximum value of 1.0 , the better it fits to the unidimensional scale. In the same way, the scalability for a single item $H_{i j}$ with respect to all the other items in the scale can be calculated:

$$
H_{i}=1-\frac{\sum_{j \neq i}^{k} F_{i j}}{\sum_{j \neq i}^{k} E_{i j}}(i \neq j)
$$

Finally, a measure for the scalability of the whole set of items is:

$$
H=1-\frac{\sum_{i=1}^{k-1} \sum_{j=i+1}^{k} F_{i j}}{\sum_{i=1}^{k-1} \sum_{j=i+1}^{k} E_{i j}}
$$

For these coefficients Mokken developed the asymptotic sampling theory and introduced a 
statistic $\Delta^{*}$ (DELTA STAR) which has approximately a standard normal distribution. This statistic allows a test of the hypothesis that, in the population, $\Delta^{*}=0$ or, equivalenty, that $H=0$. The equation for $\Delta^{*}$ is:

$\Delta^{*}=\frac{(n-1)^{1 / 2} \Delta}{\sigma_{(k)}}$

$\Delta=\sum_{i=1}^{k-1} \sum_{j=i+1}^{k} \Delta_{i j}$ and $\Delta_{i j}=E_{i j}-F_{i j}$

$\sigma_{(k)}^{2}=\sum_{i=1}^{k-1} \sum_{j=i+1}^{k} \sigma_{i j}^{2}$

$\sigma_{i j}^{2}=\hat{\pi}_{i}\left(1-\hat{\pi}_{i}\right) \hat{\pi}_{j}\left(1-\hat{\pi}_{j}\right)$

and $\hat{\pi}_{i}$ and $\hat{\pi}_{j}$ are the fractions of positive scores for items $i$ and $j$.

These coefficients can be used for the construction and testing of a scale from a given set of items. Mokken [21] postulated that $H_{i j}$-values should be at least 0.3 and preferably 0.4 or 0.5 . In his view, a scale is "good" if the $H$-values are larger than 0.5 . The $\Delta^{*}$-statistic can be used to test if $H$ and all $H_{i j}$-coefficients are significantly larger than zero.

With these scalability coefficients the internal consistency of the scale can be evaluated, but there is another restriction for the data to be taken into account: the requirement of double monotonicity. Double monotonicity means that on the one hand the degree of difficulty of the items is the same for all respondents, and on the other that for all respondents all items are ordered in the same way. Scalability coefficients refer to pairwise consistencies of answers to items, double monotonicity refers to the overall consistency. Double monotonicity can easily be checked when cross-tabulations are made for all item pairs. When these two by two tables, from left to right and from top to bottom, have been arranged from difficult to easy, checking of the ++ cells and the - - cells will show if the conditions of double monotonicity are met. To satisfy these conditions there should be a monotone increase in the ++ cells and a monotone decrease in the - - cells, to the right and the bottom. (This double monotonicity check will be carried out in the next section).

When items pass the criteria of internal consistency and double monotonicity, they can be con- sidered to form a scale, and usually the number of positively scored items is assigned as a scale value for a respondent.

Recently, a special computer program, MSP, has been developed to perform all the necessary computations and tests for the construction of a scale [6]. This Mokken Scale program for polychotomous items extends Mokken's theory for dichotomous items into a generalized theory of probabilistic scaling models for polychotomous items. For an introduction to this theory and an application of the program, see [26].

\section{Application to marketing decision support sys- tems}

\subsection{The data}

The scale was developed in the framework of a research project about the penetration and use of marketing decision support systems in Dutch companies. The responses of 525 companies in a telephone survey were available. During the interview, a marketing manager or a person of comparable rank was asked a number of questions about the company and the marketing decision support system or components thereof used in the company. From a database which contained in principle all Dutch companies with more than 10 employees, the survey sample was drawn only from those companies which employed a marketing manager. This sampling procedure implies that the respondents are favourably biased with respect to the sophistication of marketing management in their companies, compared to the universe of all Dutch companies. An important question in the survey was the following:

"Does your company have a system that is used or could be used by different persons in the organisation and that could be considered as a marketing decision support system?"

194 respondents (37\%) answered this question affirmatively. In this paper we will restrict our attention to these 194 respondents who stated that they indeed have a marketing decision support system.

These respondents subsequently answered a number of questions about their MDSS, in particular the capability of the system to perform specific analyses. There are in total thirteen such 
questions in the survey (located at different places in the interview). The items were selected in direct relationship with the Ievels of questions a MDSS is able to answer: What, Why, What-if, What should, as defined in the theory section.

These questions are given in Table 2, where it is also indicated to which of the four items they refer. There are seven questions referring to the "what" item, two which refer to the why-item, three which refer to the what-if item and one which refers to the what-should item.

In the survey for each of the items (e.g. "retrieval of data about customers") it was asked whether or not the MDSS would be used for that purpose. A "yes" would be interpreted as a positive score.

Although the most recent version of scalogram analysis can handle polychotomous items, [6], the more conventional dichotomous version was used here, because the numbers of questions that refer to each hierarchical level are different (seven for "what", one for "what-should", for example).

So for the levels what, why and what-if a recoding rule of the following type was developed: if the number of what-questions is greater than $x$, then the (composite) what-item is given a 1 , otherwise a 0 . For the what item, $x$ can in principle, vary from 0 to 6 . Also for the why and what-if item different values for $x$ are possible.

\subsection{Results}

For all the combinations of the possible recoding rules that satisfied the double monotonicity

Table 3

Recoding rules corresponding with the best solution

\begin{tabular}{|c|c|c|}
\hline Item & Score $=1$ & Score $=0$ \\
\hline What & $\begin{array}{l}\text { If more than } 2 \text { what } \\
\text { questions positive }\end{array}$ & $\begin{array}{l}\text { If } 2 \text { or less } \\
\text { what } \\
\text { questions } \\
\text { positive }\end{array}$ \\
\hline Why & $\begin{array}{l}\text { If } 1 \text { or } 2 \text { why } \\
\text { questions positive }\end{array}$ & $\begin{array}{l}\text { If } 0 \text { why } \\
\text { questions } \\
\text { positive }\end{array}$ \\
\hline What-if & $\begin{array}{l}\text { If } 2 \text { or } 3 \text { what -if } \\
\text { questions positive }\end{array}$ & $\begin{array}{l}\text { If } 0 \text { or } 1 \\
\text { what-if } \\
\text { questions } \\
\text { positive }\end{array}$ \\
\hline What should & $\begin{array}{l}\text { If what-should } \\
\text { question positive }\end{array}$ & $\begin{array}{l}\text { If what- } \\
\text { should } \\
\text { question } \\
\text { negative }\end{array}$ \\
\hline
\end{tabular}

Table 4

Cross-tabulations of frequencies for item pairs

\begin{tabular}{|c|c|c|c|c|c|c|c|c|c|c|}
\hline & \multicolumn{3}{|c|}{ What should } & \multicolumn{3}{|c|}{ What-if } & \multicolumn{3}{|c|}{ Why } & \multirow{2}{*}{$\begin{array}{l}\text { Mar- } \\
\text { ginals }\end{array}$} \\
\hline & & + & - & & & & & & & \\
\hline \multirow[t]{3}{*}{ What-if } & + & 33 & 46 & & & & & & & 79 \\
\hline & - & 9 & 106 & & & & & & & \\
\hline & & + & - & & + & - & & & & \\
\hline \multirow[t]{3}{*}{ Why } & + & 41 & 109 & + & 72 & 78 & & & & 150 \\
\hline & - & 1 & 43 & - & 7 & 37 & & & & \\
\hline & & + & - & & + & - & & + & - & \\
\hline \multirow[t]{2}{*}{ What } & + & 42 & 130 & + & 76 & 96 & + & 138 & 34 & 172 \\
\hline & - & 0 & 21 & - & 3 & 19 & - & 12 & 10 & \\
\hline Marginals & & 42 & & & 79 & & & 150 & & \\
\hline
\end{tabular}

criterion, scalability coefficients were calculated and compared. The three types of scalability coefficients mentioned before were used to find the best solution. The solution with the highest $\Delta^{*}$ was chosen. Matrices of $H_{i j}$-coefficients were calculated and the best solution was chosen for further analyses. In Table 3 the recoding rules for the best solution are given. Table 4 and Table 5 present the cross-tabulations of the item pairs and the matrix of the scalability coefficients $H_{i j}$ respectively.

Table 4 demonstrates the double-monotonicity requirement: to the right and the bottom the numbers in the ++ cells increase monotonically and the numbers in the -- cells decrease monotonically.

To illustrate: 33 respondents can perform "what-should" and "what-if" analyses, 41 respondents can perform "what-should" and "why" analyses, 42 respondents can perform "whatshould" and "what" analyses. From the marginals in Table 4 it can be concluded that of the 194 respondents who claim to have an MDSS, 172 can answer "what"-questions, 150 can answer "why"-questions, 79 can answer "what-if"-questions and 42 can answer "what-should"-questions.

Table 5

Matrix of $H_{i j}$

\begin{tabular}{lllll}
\hline & What & Why & What-if & What should \\
\hline What & - & & & \\
Why & 0.29 & - & & \\
What-if & 0.67 & 0.61 & - & \\
What should & 1.00 & 0.90 & 0.64 & - \\
\hline
\end{tabular}


Table 6

Distribution of the MDSS over the scale

\begin{tabular}{lllllll}
\hline & \multicolumn{3}{l}{ Scale score } & & Total \\
\cline { 2 - 6 } & 0 & 1 & 2 & 3 & 4 & \\
\hline Number & 8 & 41 & 66 & 46 & 33 & 194 \\
Percentage & $4 \%$ & $21 \%$ & $34 \%$ & $24 \%$ & $17 \%$ & $100 \%$ \\
\hline
\end{tabular}

As Table 5 shows, except for the $\mathrm{H}_{\mathrm{ij}}$-value for the what and why pair, all values are well above Mokken's lower boundary for a "good" score of 0.50 . For the "what" and "what-should" pair the coefficient equals 1.00 , which means that no violations are found, meaning there are no systems that score positively for the what should-item and negatively for the what-item.

For the total scale, the scalability coefficient $\mathrm{H}$ is 0.61 and the corresponding $\Delta^{*}=8.82$, which clearly implies significance.

This means that an unidimensional hierarchical scale has been constructed here, which meets the requirements of scalability and double monotonicity. This will be called the Hierarchical MDSS Sophistication (HMS) scale. Each company obtains a score for this scale which is simply equal to the number of composite items (what, why, what-if, what-should) on which it is positive. Of course the recoding rules of Table 3 are applied to deduce the items scores from the answers to the questions in the survey.

The resulting score of a company on the HMS scale can range from 0 to 4 .

Table 6 depicts the distribution along the scale of the 194 companies that reported having an MDSS.
As this table shows, the distribution looks somewhat similar to a normal distribution, but with a bias to the right. It should be borne in mind however the distribution was truncated heavily at the left end by leaving out all the companies in the analysis which stated that they did not have a MDSS

\section{Correlation of the HMS scale with company variables}

In the last section the internal consistency (scalability and double monotonicity) of the HMS-scale was tested. Here, the correlation of the scale by computing the correlation between the HMS-score and a number of external variables was examined.

"Although this analysis cannot be qualified as a formal validity test of the HMS-scale [8, p. 251] it provides at least some information with respect to the content validity of the scale."

The sophistication of the MDSS of a company is expected to be positively correlated with the variables listed in Table 7 . These variables were measured along with the information on MDSS sophistication, in the telephone survey.

For the variables 1 to 4 somewhat elaborated results are presented below. The correlation coefficients for all the variables can be found in Table 12.

\subsection{Annual revenue}

Table 8 gives the relationship between the HMS score and annual revenue. (The annual

Table 7

Variables that are predicted to correlate positively with the HMS score

\begin{tabular}{ll}
\hline 1 & Size of company in terms of annual revenue \\
2 & Size of company in terms of number of employees \\
3 & The extent to which the company sells consumer products, as compared to business-to-business products. \\
4 & Whether or not the company has a specialized marketing department. \\
5 & Size of the marketing department: number of marketing professionals as well as support staff. \\
6 & Whether or not the company has a specialized market research department. \\
7 & Size of the marketing research department in terms of number of employees. \\
8 & Number of PC's, terminals and workstations in the marketing department. \\
9 & Investment costs of MDSS. \\
10 & Annual maintenance costs of MDSS. \\
11 & Number of different data sources used (from a total of nine sources mentioned in the survey). \\
12 & Importance attached to information (The response on a five-point scale to the statement: 'Our company puts much \\
13 & emphasis on the gathering and analysis of information before major decisions are made'). \\
\end{tabular}


Table 8

Breakdown of the scores on the HMS-scale for annual revenue classes

\begin{tabular}{|c|c|c|c|c|c|c|c|c|}
\hline & \multicolumn{5}{|c|}{ Score on HMS-scale } & \multicolumn{3}{|c|}{ Total } \\
\hline & 0 & 1 & 2 & 3 & 4 & $\mathrm{~N}$ & Aver. & Stdv. \\
\hline TOTAL & $5 \%$ & $21 \%$ & $33 \%$ & $24 \%$ & $18 \%$ & 169 & 2.30 & 1.13 \\
\hline \multicolumn{9}{|l|}{ Annual revenu (in US dollars): } \\
\hline$<0.5$ million $\$$ & $0 \%$ & $50 \%$ & $50 \%$ & $0 \%$ & $0 \%$ & 2 & 1.50 & 0.71 \\
\hline $0.5-2.5$ million $\$$ & $0 \%$ & $33 \%$ & $33 \%$ & $0 \%$ & $33 \%$ & 3 & 2.33 & 1.53 \\
\hline $2.5-12.5$ million $\$$ & $10 \%$ & $19 \%$ & $29 \%$ & $32 \%$ & $10 \%$ & 31 & 2.13 & 1.15 \\
\hline $12.5-50$ million $\$$ & $6 \%$ & $28 \%$ & $33 \%$ & $19 \%$ & $14 \%$ & 64 & 2.06 & 1.14 \\
\hline $50-125$ million $\$$ & $3 \%$ & $14 \%$ & $36 \%$ & $28 \%$ & $19 \%$ & 36 & 2.47 & 1.06 \\
\hline$>125$ million $\$$ & $0 \%$ & $12 \%$ & $30 \%$ & $27 \%$ & $30 \%$ & 33 & 2.76 & 1.03 \\
\hline
\end{tabular}

revenue figure was only available for 169 of the 194 companies in the sample.) Here, the annual revenue either refers to the whole company or to a specific business unit, i.e. in cases when the marketing activity of the respondents applied only to that specific business unit. (The same applies to the variable: number of employees in Table 9).

Table 8 shows that, although not completely monotonic, there is a tendency that companies with higher annual revenue have more sophisticated MDSS. The correlation is significant (see Table 12).

\subsection{Number of employees}

No relationship is found between the number of employees and the score on the HMS-scale. With an exception for the category 20-49 employees, the average score per category differs only slightly (see Table 9).

\subsection{Consumer marketing versus business-to-busi- ness marketing}

With respect to the kind of products (or services) companies sell, a distinction is made be- tween consumer products and business-to-business products. The buyers of the latter category of products are organizations instead of consumers. The respondents were asked what part of their total revenue could be attributed to consumer products.

As can be concluded from Table 10, the higher the proportion of consumer products of a company the higher the level of sophistication of its MDSS $(p=0.01)$. This is also illustrated by the average score on the HMS-scale: companies selling primarily consumer products have an average score of 2.60 , whereas companies selling primarily business to business products have an average score of only 2.12 .

This result could be expected, because the application of analytical tools to support marketing management so far has been more frequent in consumer product companies than in industrial product companies.

\subsection{The organization of the marketing function}

With respect to the way the marketing function has been organized in a company three

Table 9

Breakdown of the scores on the HMS-scale for number of employees classes

\begin{tabular}{|c|c|c|c|c|c|c|c|c|}
\hline & \multicolumn{5}{|c|}{ Score on HMS-scale } & \multicolumn{3}{|c|}{ Total } \\
\hline & 0 & 1 & 2 & 3 & 4 & $\mathrm{~N}$ & Aver. & stdv \\
\hline TOTAL & $4 \%$ & $21 \%$ & $34 \%$ & $24 \%$ & $17 \%$ & 194 & 2.28 & 1.10 \\
\hline \multicolumn{9}{|c|}{ Number of employees: } \\
\hline$<20$ employees & $8 \%$ & $15 \%$ & $38 \%$ & $23 \%$ & $15 \%$ & 13 & 2.23 & 1.17 \\
\hline $20-49$ & $10 \%$ & $35 \%$ & $20 \%$ & $20 \%$ & $15 \%$ & 20 & 1.95 & 1.28 \\
\hline $50-99$ & $0 \%$ & $21 \%$ & $36 \%$ & $32 \%$ & $11 \%$ & 28 & 2.32 & 0.94 \\
\hline $100-199$ & $3 \%$ & $27 \%$ & $30 \%$ & $23 \%$ & $17 \%$ & 30 & 2.23 & 1.14 \\
\hline $200-499$ & $6 \%$ & $14 \%$ & $38 \%$ & $22 \%$ & $20 \%$ & 50 & 2.36 & 1.14 \\
\hline$>500$ employees & $2 \%$ & $21 \%$ & $36 \%$ & $23 \%$ & $19 \%$ & 53 & 2.36 & 1.08 \\
\hline
\end{tabular}


Table 10

Breakdown of the scores on the HMS-scale for consumer marketing or business-to-business marketing

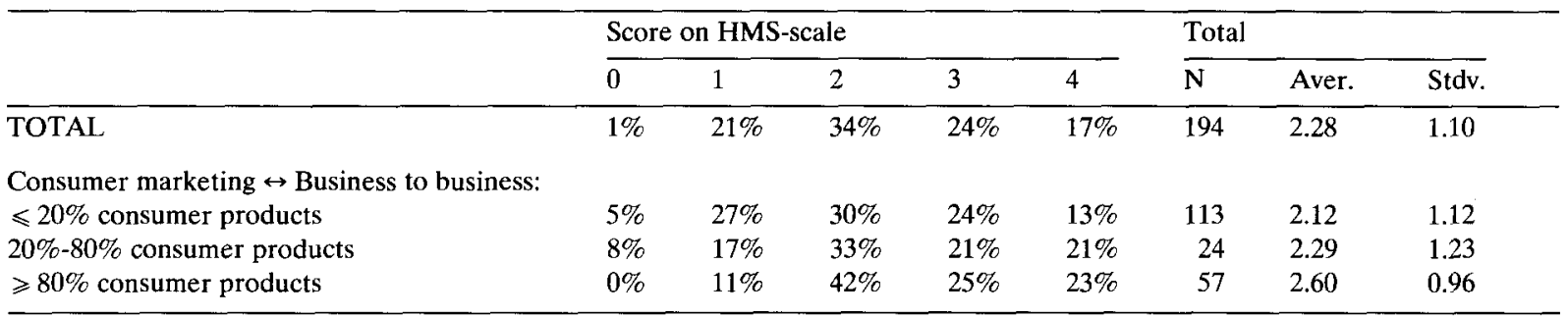

groups of companies are distinguished: companies without a separate marketing department, companies with one marketing department and companies with more than one marketing department.

Table 11 shows that companies without a marketing department have a much lower average score (1.63) than companies with one or more than one marketing department (2.29 and 2.87) $(p=0.00)$. This means that, as expected, the "stronger" the organization of the marketing function the higher the level of sophistication of the MDSS.

Table 12 gives all the correlation coefficients that were computed to establish criterion validity of the HMS-scale. All but one (annual maintenance costs) of the correlations are in the expected direction. Eight of the fourteen correlation coefficients are also significant.

A company has a significantly higher HMS score as/when:

- the annual revenue is higher

- the company is predominantly selling consumer products

- the company has a separate marketing department
- the company has more supporting personnel in the marketing department

- the company has a market research department

- the company has more PC's, terminals and workstations in the marketing department

- the company uses more data sources

- the company is perceived as more innovative

To comment on a few of the other outcomes: Apparently, a larger number of marketing professionals in the marketing department does not lead to a higher sophistication of the MDSS. The significant correlation of HMS-scores with number of support staff reflects the fact that for advanced systems more specialized persons are needed: programmers, system developers, system administrators etc., however this is not reflected in higher total costs for more sophisticated MDSS (costs include personnel costs).

A very important outcome is the high correlation coefficient for number of different data sources. Apparently a sophisticated MDSS goes together with availability of many data. Data availability may be stimulated by the desire to develop a more sophisticated MDSS. The other way around: data availability is also a favorable

Table 11

Breakdown of the scores on the HMS-scale for different organisations of the marketing function

\begin{tabular}{|c|c|c|c|c|c|c|c|c|}
\hline & \multicolumn{5}{|c|}{ Score on HMS-scale } & \multicolumn{3}{|c|}{ Total } \\
\hline & 0 & 1 & 2 & 3 & 4 & $\mathrm{~N}$ & Aver. & Stdv \\
\hline TOTAL & $4 \%$ & $21 \%$ & $34 \%$ & $24 \%$ & $17 \%$ & 194 & 2.28 & 1.10 \\
\hline \multicolumn{9}{|l|}{ Organization of the marketing function: } \\
\hline No separate marketing department & $10 \%$ & $43 \%$ & $27 \%$ & $13 \%$ & $7 \%$ & 30 & 1.63 & 1.07 \\
\hline One marketing department & $4 \%$ & $18 \%$ & $38 \%$ & $25 \%$ & $15 \%$ & 133 & 2.29 & 1.05 \\
\hline More than one marketing department & $0 \%$ & $13 \%$ & $23 \%$ & $29 \%$ & $35 \%$ & 31 & 2.87 & 1.06 \\
\hline
\end{tabular}


Table 12

Correlation coefficients of the score on the HMS-scale with external variables

\begin{tabular}{|c|c|c|c|}
\hline & Variable & $\begin{array}{l}\text { Correlation } \\
\text { coefficient } \\
\text { (Pearson) }\end{array}$ & $\begin{array}{l}p- \\
\text { level } \\
\text { (two- } \\
\text { sided) }\end{array}$ \\
\hline 1 & Size of company: & & \\
\hline & Annual revenue & 0.22 & 0.00 \\
\hline 2 & Size of company: & & \\
\hline & Number of employees & 0.08 & 0.28 \\
\hline 3 & $\begin{array}{l}\text { Percentage of revenues from } \\
\text { consumer products }\end{array}$ & 0.17 & 0.01 \\
\hline 4 & $\begin{array}{l}\text { Number of marketing } \\
\text { departments }(0,1,2)\end{array}$ & 0.31 & 0.00 \\
\hline 5 & $\begin{array}{l}\text { Size of marketing department } \\
\text { (a) number of marketing } \\
\text { professionals } \\
\text { (b) number of support }\end{array}$ & 0.08 & 0.26 \\
\hline & staff & 0.25 & 0.01 \\
\hline 6 & $\begin{array}{l}\text { Market research department } \\
(\text { Yes }=1 \text { No }=0)\end{array}$ & 0.19 & 0.01 \\
\hline 7 & $\begin{array}{l}\text { Size of marketing research } \\
\text { dept. (\# of employees) }\end{array}$ & 0.11 & 0.68 \\
\hline 8 & $\begin{array}{l}\text { Number of PC terminals and } \\
\text { workstations in marketing } \\
\text { department }\end{array}$ & 0.13 & 0.08 \\
\hline 9 & Investment costs of MDSS & 0.09 & 0.47 \\
\hline 10 & $\begin{array}{l}\text { Annual maintenance costs of } \\
\text { MDSS }\end{array}$ & -0.06 & 0.72 \\
\hline 11 & $\begin{array}{l}\text { Number of different data } \\
\text { sources used }\end{array}$ & 0.45 & 0.00 \\
\hline 12 & $\begin{array}{l}\text { Importance attached to } \\
\text { information }\end{array}$ & 0.10 & 0.17 \\
\hline 13 & Innovativeness & 0.16 & 0.02 \\
\hline
\end{tabular}

condition for more sophisticated MDSS. On the whole the picture of correlation coefficients in Table 12 constitutes support for the validity of the HMS scale developed in this paper.

\section{Conclusion and perspectives}

In this paper a hierarchical scale: the Hierarchical Marketing Decision Support Systems Scale (HMS) was developed for the level of sophistication of MDSS in companies. To determine the position of a company on this scale, questions have to be asked about the capabilities of its system with respect to data retrieval, data analysis, the simulation of marketing policies and search for the best policy.

The scale was developed by using Guttman's scalogram analysis and the items were found to possess the required properties of scalability and double monotonicity.

The "managerial validity" of the scale was demonstrated by the relationship between a company's score on the HMS and a large number of managerially relevants aspect of a company.

The successful development of this scale opens perspectives for further research. The authors use this scale in their own work to study the adoption and diffusion process of MDSS in companies. Another research path is to develop a similar scale to classify DSS in other functional areas of management (finance, production etc.). An interesting question is whether or not the same company characteristics will be found to correlate with the sophistication levels of financial DSS or production DSS as where observed for Marketing DSS.

In general, the development and use of these scales will contribute to a more unified approach in the empirical study of (M)DSS, an area where up to now an ad hoc approach seems to be dominant.

\section{References}

[1] S.L. Alter (1975), A Study of Computer Aided Decision Making in Organizations, Ph.D. diss, Massachuttes Institute of Technology.

[2] S.L. Alter (1977), A Taxonomy of Decision Support Systems, Sloan Management Review, Fall, 39-56.

[3] S.L. Alter (1980), Decision Support Systems: Current Practice and Continuing Challenges, Reading MA: Addison Wesley Publishing Company.

[4] J.J. Brennan en J.J. Elam (1986), Understanding and Validating Results in Model-Based Decision Support Systems, Decision Support Systems,2, p. 49-54.

[5] D.A. Brown, S.F. Buck and F.G. Pyatt (1965), Improving the sales forecast for consumer durables, Journal of Marketing Research, 2, 229-234.

[6] P. Debets and E. Brouwer (1989), MSP: A Program for Mokken Scale Analysis for Polychotomous Items, Groningen, ProGAMMA

[7] C. Dell'Aquila, E. Fefons, F. Tangorra, L. Colarro (1989), Architecture of a Relational Decision Support System, Decision Support Systems, 5, p. 65-78.

[8] P.E. Green, D.S. Tull and G. Albaum (1988), Research for Marketing Decisions, 5th Ed., Englewood Cliffs NJ, Prentice Hall.

[9] L. Guttman (1944), A basis for scaling qualitative data, American Sociological Review, 9, 139-150, (reprinted in G.F. Summers (ed.), 1970, Attitude Measurement, Chicago: Rand McNally, 174-186).

[10] M. Jarke and F.J. Radermacher (1988), The AI Potential of Model Management and Its Central Role in Decision 
Support Systems, Decision Support Systems, 4, p. 387404.

[11] P.G.W. Keen and M.S. Scott Morton (1978), Decision Support Systems: An Organisational Perspective, Reading MA: Addison Wesley.

[12] B. Konsynski and R.H. Sprague Jr. (1986), Future Research Directions in Model Management, Decision Support Systems, 2, p. 103-109.

[13] J.B. Landis (1965), Exposure probabilities as measures of media audiences, Journal of Advertising Research, 5, 24-29.

[14] J.D.C. Little (1970), Models and Managers, The Concept of a Decision Calculus, Management Science, 16 (April), B466-489.

[15] J.D.C. Little (1979), Decision Support Systems for Marketing Managers, Journal of Marketing, 43, Summer, 9-26.

[16] J. Loevinger (1947), A systematic approach to the construction and evaluation of tests of ability, Psychological Monographs, 61 , no. 4.

[17] J. Loevinger (1948), The technic of homogeneous tests compared with some aspects of 'scale analysis' and factor analysis, Psychological Bulletin, 45, 507-530.

[18] A.L. McCutcheon (1987), Latent Class Analysis, Newbury, Park: Sage Publications, Quantitive applications in the Social Sciences, 64.

[19] J. McFall (1969), Priority patterns and consumer behavior, Journal of Marketing, 33, 50-55.

[20] H. Min (1989), A Model-Based Decision Support System for Locating Banks, Information and Management, 17, p. 207-215.

[21] R.J. Mokken (1971), A theory and procedure of scale analysis, 's-Gravenhage: Mouton.

[22] D.B. Montgomery and G.L. Urban (1969), Management
Science in Marketing, Englewood Cliffs NJ, Prentice Hall.

[23] T. Ottinger and M. Grünerwald (1984), Changing Marketing Problems Require Flexible MMIS Approaches, Seminar on Market Research and M.M.I.S.: The Gap is Closing, Geneva (Switzerland), 25-27 January, p. 77-101.

[24] A. Sen and J. Choobinek (1990), Deductive Data Modeling: A New Trend in Database Management for Decision Support Systems, Decision Support Systems, 6, p. 45-57.

[25] M.J. Shaw, P.L. Tu and P. De (1988), Applying Machine Learning to Model Management in Decision Support Systems, Decision Support Systems, 4, p. 285-305.

[26] K. Sijtsma, P. Debets and I.W. Molenaar (1990), Mokken scale analysis for polychotomous items: theory, a computer program and an empirical application, Quality and Quantity, 24, 173-188.

[27] L.D. Smith, J. Blodgett en M. Janson (1985), Decision Support for Marketing Research and Corporate Planning, Information and Management, 8, p. 133-145.

[28] R.H. Sprague and H.J. Watson (eds) (1989), Decision Support Systems (sec.ed), Englewood Cliffs NJ, Prentice Hall.

[29] R.H. Sprague (1980), A Framework for the Development of Decision Support Systems, MIS Quartely, 4 (December).

[30] R.H. Sprague, Jr. en E.D. Carlson (1982), Building Effective Decision Support Systems, Prentice Hall, Inc. Englewood Cliffs, New Jersey.

[31] V. Srinivasan and Y.H. Kim (1986), Decision Support for Integrated Cash Management, Decision Support Systems, 2, p.347-363.

[32] W.S. Torgerson (1958), Theory and methods of scaling, New York: J. Wiley. 